\title{
The study of the consequences of preserving berry crops in vitro on the processes of subsequent clonal micropropagation
}

\author{
Inna Knyazeva * \\ Federal State Budgetary Scientific Institution «Federal Scientific Agroengineering Center VIM», All-Russian Horticultural Institute \\ for Breeding, Agrotechnology and Nursery Moscow, Russia
}

\begin{abstract}
As a result of studies, it was found that collection samples of berry crops in vitro can be maintained in viable condition on specially selected nutrient media for 12 months. The effect of mannitol concentration $(0.45,0.75$ and $1.05 \%$; sucrose control - $3 \%)$ on the regenerative potential of microprobe of the studied berry crop varieties was estimated. When studying the effect of the reproduction cycle on the morphogenesis of meristemic cultures, it was found that the dynamics of changes in shoot length, number of leaves and shoots depended on the concentration of the active substance. In general, the majority of berry crops that were viable after storage of explants retained the ability to grow again, in many cases reaching or exceeding the control level.
\end{abstract}

\section{Introduction}

Plant genetic resources serve as a strategic basis for the effective stable development not only of agriculture, but also of all sectors of the economy and social sphere of the Russian Federation and the world as a whole [1-3]. Improving biotechnological methods and techniques will allow for a long time to save plant objects and create doublet genetic collections in controlled environmental conditions. Preservation of plants using techniques for culturing cells, tissues and organs in vitro is the safest alternative for reproduction and long-term maintenance of a large number of cultures $[4,5]$.

To increase the interval between passages various techniques are used based on slowing down the growth of test plants, the most important of which is not only temperature, but also the mineral composition of the nutrient medium, carbohydrate content and biologically active substances [6]. Raspberry and strawberry shoots can be stored in vitro for 24 months [7] or longer at 2-4 ${ }^{\circ} \mathrm{C}$ on media without growth regulators, although multiplication after storage is significantly lowered [8].

A feature of in vitro scientific work is the development of clonal micropropagation protocols for each variety and genotype, taking into account biological characteristics. [9].

At the Research Institute of Pomology and Floriculture (Poland) three-millimeter-long shoot tips of strawberry 'Senga Sengana' and raspberry 'Norna' encapsulated in calcium alginate were stored in vitro at $4 \circ \mathrm{C}$ in the dark. Regrowth ability of the stored explants and in vitro multiplication in three successive subcultures were evaluated. The multiplication rate of strawberry and raspberry shoots in the first subculture after storage was lower than that of non-stored cultures. Multiplication of strawberry in the second subculture was generally higher than in non-stored cultures, but multiplication of raspberry was lower also in the second subculture, with the exception of the combination stored for 9 months and pre-cultured on mannitol. In the third subculture, shoot multiplication in both species was similar to that in non-stored cultures [10].

Nodal segments (Rubus spp.) of the 'Guarani', 'Caingangue', 'Ébano', and 'Xavante' genotypes were conserved under minimal growth conditions at $20^{\circ} \mathrm{C}$, for 15 months. Microshoots were regenerated and multiplied by up to five successive subcultures, when they were rooted and acclimatized. After 30 days of acclimatization in a greenhouse, rooted plantlets showed no significant losses. Blackberry cultivars can be conserved in vitro for 15 months, without subcultures and, after this time, they can be micropropagated on a large-scale, maintaining the regenerative potential and multiplication [11].

Berry crop regeneration protocols are available for different varieties, however, there is limited information on individual varietal and hybrid profiles in the direction of restoring explant viability after direct cultivation in vitro.

The purpose of these studies was to establish the patterns of the aftereffect of medium-term conservation of in vitro berry culture explants on the processes of subsequent clonal micropropagation.

\section{Experimental}

Studies on the maintenance and restoration of the regenerative ability of explants of berry crops: Ribes nigrum L. (variety 'Bryanskiy Agat') Fragaria $x$ ananassa Duch. (variety 'Nashe Podmoskov'e') and Rubus idaeus L. (cultivar 'Bryanskoe Divo') were conducted in the biotechnology laboratory at the AllRussian Horticultural Institute for Breeding, Agrotechnology and Nursery (Moscow). 
As initial explants, shoots of approximately $1.5 \mathrm{~cm}$ long were used, which were placed in test tubes $(150 \times 160 \mathrm{~mm})$ pre-sterilized with dry heat $\left(150-200^{\circ} \mathrm{C}\right)$ with $10 \mathrm{ml}$ of agarized Murashige and Skoog nutrient medium (MS) supplemented with mannitol in concentrations $\quad 0.45 \%$ (A), $0.75 \%$ (B), $1.05 \%$ (C), sucrose control $3 \%$ and $0.7 \mathrm{mg} \mathrm{L}^{-1}$ 6-benzylaminopurine (BAP), $0.1 \mathrm{mg} \mathrm{L}^{-1}$ indole-3-butyric acid (IBA) and $8 \mathrm{~g} \mathrm{~L}^{-}$ ${ }^{1}$ agar-agar (Panreac, Spain), $\mathrm{pH}$ 5.7. At this stage, the explants were cultivated for up to 12 months in a Liebherr refrigerator (Germany) at a temperature of $4 \pm 2^{\circ} \mathrm{C}$, an illumination intensity of $70-80 \mu \mathrm{M} \mathrm{m} 2 \mathrm{~s}^{-1}$ and a photoperiod of $8 / 16$ hours.

After medium-term depositing, the shoots were transferred to $100 \mathrm{~mL}$ glass jars containing $20 \mathrm{~mL}$ of MS medium supplemented with $1.0 \mathrm{mg} \mathrm{L}^{-1} \quad 6-$ benzylaminopurine (BAP) and 3\% sucrose. Evaluation of the regenerative ability (shoot height, number of leaves and number of shoots per explant) of the explants was carried out in the climatic chamber KS-200 (Russia) under standard conditions $\left(24 \pm 2^{\circ} \mathrm{C}, 16\right.$-hour photoperiod and illumination of 3000-5000 lux) for three consecutive (after 45 days) subcultures.

For statistical analysis, we used the variance analysis, and the averages were compared by the Tukey's (HSD test) test, at a 5\% probability, calculated by the Stat Nov. The experimental design was completely randomized. Maintaining the Integrity of the Specifications.

\section{Results and discussion}

As a result of studies it was found that collection samples of berry crops in vitro can be maintained in a viable state for 12 months on specially selected nutrient media (Fig 1)

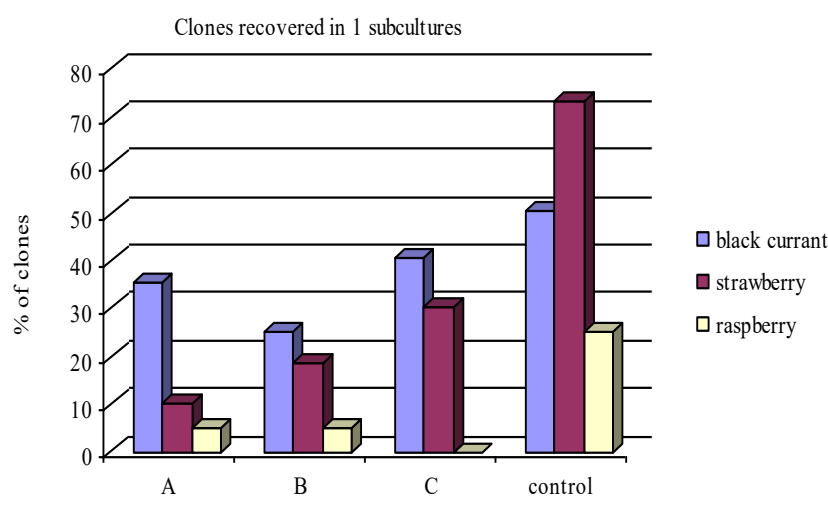

Fig. 1. The effect of mannitol concentration on the viability of explants of berry crops after 12 months of storage at $4^{\circ} \mathrm{C}$

When microboots were transferred to standard conditions after medium-term storage at $4 \pm 2^{\circ} \mathrm{C}$, the number of shoots capable of regeneration in blackcurrant on a medium with mannitol was $40.3 \%$ and $50.1 \%$ on a nutrient medium with sucrose. While maintaining garden strawberries, a decrease in viable explants in the nutrient medium with the addition of mannitol to $30.1 \%$ was noted compared to control samples $-73.3 \%$. After 12 months, only $5.0 \%$ of raspberry shoots on mannitol medium and $25.0 \%$ on sucrose were viable.
For three passages under standard cultivation conditions, after a medium-term deposit, a change in the morphometric characteristics of berry crops was observed.

In strawberry, after deposition on media with different concentrations of mannitol, all studied parameters were lower or at the level of the control variant. No significant differences in shoot height were found in the third subculture in variants $\mathrm{A}$ and $\mathrm{C}$. Explants cultivated on medium with mannitol at a concentration of $0.75 \%$ (variant B) averaged $2.81 \mathrm{~cm}$ in size. The effect of mannitol on leaf formation has also been established. For variety 'Nashe Podmoskov'e', the number of leaves in all variants of the experiment varied between 10-13 pieces. For the formation of new shoots, the best results were obtained when the explants were preserved in a medium with sucrose (control) or with mannitol in a reduced concentration of $0.45 \%$ (option A) from micrograins developed on average up to $3.10-3.33$ pcs. new shoots (Table 1).

After transfer to under standard conditions, all black currant explants were capable of active regeneration. A significant effect of mannitol concentration on shoot height and the number of leaves and shoots was established. Mannitol in the medium for medium-term storage had a positive effect on the subsequent regenerative ability of the variety 'Bryanskiy Agat' explants, in which the number of regenerated shoots increased with subsequent subculture. The maximum breeding rate ( 3.80 sprouts per explant) was observed in the 3 rd passage of cultivation after the medium with mannitol $0.45 \%$. In addition, mannitol improves the quality of microprobe, increases the number of leaves and the length of shoots (Table 2).

It was noted that the addition of mannitol to the nutrient medium at various concentrations reduced the preservation of viable raspberry explants in comparison with the addition of sucrose in relation to other cultures (strawberry and black currant). After 12 months of direct cultivation, the shoots died completely on a medium with mannitol at a concentration of $1.05 \%$ (option C). The effect of storage and the concentration of mannitol on the regenerative capacity of explants cultivar 'Bryanskoe Divo' shows that the best morphometric indicators were observed in shoots that were obtained during cultivation at storage on a medium with sucrose. When mannitol was introduced into the nutrient medium, it did not reveal its significant effect both on the number of leaves and shoots, and on the size of the shoots; all parameters were lower or within control. It should be noted that after the action of mannitol, inhibition of shoots growth is observed, which can help extend the terms of replantation (Table 3 ).

The results suggest that genotype-affected behaviour when cold-stored cultures were replaced into the multiplication medium under standard conditions. The optimal sources of carbon nutrition (mannitol and sucrose) of the nutrient medium were revealed, which provide a significant positive effect of the restoration of regenerative ability after prolonged storage in vitro: for blackcurrant medium with the addition of mannitol, for wild strawberry and raspberry, the maximum 
development of explants was observed on the medium with the addition of sucrose (Fig. 2).

Table 1. Mean shoot height, number of leaves, and number of shoots explant of strawberry 'Nashe podmoskovie' under standard conditions

\begin{tabular}{|c|c|c|c|c|}
\hline \multirow{3}{*}{ Treatment } & \multicolumn{3}{|c|}{ Subcultures } & \multirow[t]{2}{*}{ Mean } \\
\hline & 1 & 2 & 3 & \\
\hline & \multicolumn{4}{|c|}{ Shoot height $(\mathrm{cm})$} \\
\hline $\mathrm{A}$ & $2.11 \pm 0.06$ & $2.96 \pm 0.12$ & $6.45 \pm 0.28$ & $3.84 \pm 0.15$ \\
\hline $\mathrm{B}$ & $1.59 \pm 0.02$ & $2.74 \pm 0.08$ & $4.10 \pm 0.12$ & $2.81 \pm 0.07$ \\
\hline $\mathrm{C}$ & $1.63 \pm 0.03$ & $2.38 \pm 0.08$ & $6.11 \pm 0.42$ & $3.37 \pm 0.17$ \\
\hline control & $3.34 \pm 0.14$ & $3.92 \pm 0.12$ & $6.79 \pm 0.32$ & $4.68 \pm 0.19$ \\
\hline Mean & $2.17 \pm 0.06$ & $3.00 \pm 0.11$ & $5.86 \pm 0.28$ & \multirow[t]{2}{*}{-} \\
\hline $\begin{array}{c}\text { Least significant differences }(\mathrm{P}< \\
0.05)\end{array}$ & 0.22 & 0.30 & 0.87 & \\
\hline & \multicolumn{4}{|c|}{ Number of leaves } \\
\hline $\mathrm{A}$ & $6.50 \pm 0.22$ & $13.30 \pm 0.94$ & $19.20 \pm 0.59$ & $13.0 \pm 0.58$ \\
\hline $\mathrm{B}$ & $3.70 \pm 0.15$ & $12.20 \pm 0.44$ & $15.00 \pm 0.53$ & $10.3 \pm 0.37$ \\
\hline $\mathrm{C}$ & $4.20 \pm 0.29$ & $10.70 \pm 0.53$ & $18.80 \pm 0.8^{\text {n.s. }}$ & $11.2 \pm 0.54$ \\
\hline control & $6.90 \pm 0.31$ & $16.60 \pm 0.42$ & $20.00 \pm 0.66$ & $14.5 \pm 0.46$ \\
\hline Mean & $5.32 \pm 0.25$ & $13.20 \pm 0.58$ & $18.25 \pm 0.66$ & \multirow[b]{2}{*}{-} \\
\hline $\begin{array}{c}\text { Least significant differences }(\mathrm{P}< \\
0.05)\end{array}$ & 0.72 & 1.77 & 1.86 & \\
\hline & \multicolumn{4}{|c|}{ Number of shoots per explant } \\
\hline $\mathrm{A}$ & $2.10 \pm 0.23$ & $3.10 \pm 0.23$ & $4.20 \pm 0.20$ & $3.10 \pm 0.22$ \\
\hline B & $1.40 \pm 0.30$ & $2.20 \pm 0.24$ & $2.70 \pm 0.21$ & $2.10 \pm 0.25$ \\
\hline $\mathrm{C}$ & $1.50 \pm 0.22$ & $1.80 \pm 0.24$ & $4.10 \pm 0.23$ & $2.50 \pm 0.23$ \\
\hline control & $2.80 \pm 0.20$ & $3.20 \pm 0.20$ & $4.00 \pm 0.21$ & $3.33 \pm 0.20$ \\
\hline Mean & $1.95 \pm 0.23$ & $2.58 \pm 0.22$ & $3.75 \pm 0.21$ & \multirow{2}{*}{ (1) } \\
\hline $\begin{array}{c}\text { Least significant differences }(\mathrm{P}< \\
0.05)\end{array}$ & 0.69 & 0.66 & 0.63 & \\
\hline
\end{tabular}

Table 2. Mean shoot height, number of leaves, and number of shoots explant of black currant 'Bryanskiy Agat' under standard conditions

\begin{tabular}{|c|c|c|c|c|}
\hline \multirow{3}{*}{ Treatment } & \multicolumn{3}{|c|}{ Subcultures } & \multirow[t]{2}{*}{ Mean } \\
\hline & 1 & 2 & 3 & \\
\hline & \multicolumn{4}{|c|}{ Shoot height $(\mathrm{cm})$} \\
\hline $\mathrm{A}$ & $3.13 \pm 0.11$ & $8.20 \pm 0.64$ & $8.79 \pm 0.34$ & $6.71 \pm 0.36$ \\
\hline $\mathrm{B}$ & $2.54 \pm 0.13$ & $7.79 \pm 0.49$ & $8.73 \pm 0.26$ & $6.30 \pm 0.29$ \\
\hline $\mathrm{C}$ & $2.16 \pm 0.18$ & $7.37 \pm 0.48$ & $9.10 \pm 0.40$ & $6.21 \pm 0.35$ \\
\hline control & $2.48 \pm 0.15$ & $4.77 \pm 0.66$ & $6.49 \pm 0.40$ & $4.58 \pm 0.40$ \\
\hline Mean & $2.58 \pm 0.15$ & $7.03 \pm 0.53$ & $8.28 \pm 0.36$ & \multirow[b]{2}{*}{ - } \\
\hline $\begin{array}{c}\text { Least significant differences }(\mathrm{P}< \\
0.05)\end{array}$ & 0.41 & 1.50 & 1.01 & \\
\hline & \multicolumn{4}{|c|}{ Number of leaves } \\
\hline $\mathrm{A}$ & $4.60 \pm 0.22$ & $9.00 \pm 0.21$ & $9.20 \pm 0.32$ & $7.60 \pm 0.25$ \\
\hline $\mathrm{B}$ & $3.90 \pm 0.23$ & $9.60 \pm 0.31$ & $9.20 \pm 0.32$ & $7.57 \pm 0.28$ \\
\hline $\mathrm{C}$ & $3.80 \pm 0.32$ & $8.50 \pm 0.26$ & $9.80 \pm 0.29$ & $7.40 \pm 0.29$ \\
\hline control & $4.60 \pm 0.22$ & $7.40 \pm 0.52$ & $9.10 \pm 0.31$ & $7.03 \pm 0.35$ \\
\hline Mean & $4.23 \pm 0.25$ & $8.36 \pm 0.35$ & $9.32 \pm 0.31$ & \multirow[b]{2}{*}{-} \\
\hline $\begin{array}{c}\text { Least significant differences }(\mathrm{P}< \\
0.05)\end{array}$ & 0.70 & 0.98 & 0.89 & \\
\hline & \multicolumn{4}{|c|}{ Number of shoots per explant } \\
\hline $\mathrm{A}$ & $1.70 \pm 0.33$ & $1.80 \pm 0.25$ & $3.80 \pm 0.25$ & $2.43 \pm 0.28$ \\
\hline $\mathrm{B}$ & $1.60 \pm 0.27$ & $1.70 \pm 0.21$ & $2.60 \pm 0.16$ & $1.97 \pm 0.21$ \\
\hline $\mathrm{C}$ & $1.30 \pm 0.21$ & $1.90 \pm 0.28$ & $3.20 \pm 0.29$ & $2.13 \pm 0.26$ \\
\hline control & $1.50 \pm 0.31$ & $1.30 \pm 0.26$ & $2.10 \pm 0.18$ & $1.63 \pm 0.25$ \\
\hline Mean & $1.52 \pm 0.28$ & $1.68 \pm 0.25$ & $2.90 \pm 0.70$ & \multirow[b]{2}{*}{-} \\
\hline $\begin{array}{c}\text { Least significant differences }(\mathrm{P}< \\
0.05)\end{array}$ & 0.80 & 0.72 & 0.63 & \\
\hline
\end{tabular}


Table 3. Mean shoot height, number of leaves and number of shoots explant of black raspberry 'Bryanskoe Divo' under standard conditions

\begin{tabular}{|c|c|c|c|c|}
\hline \multirow{3}{*}{ Treatment } & \multicolumn{3}{|c|}{ Subcultures } & \multirow[t]{2}{*}{ Mean } \\
\hline & 1 & 2 & 3 & \\
\hline & \multicolumn{4}{|c|}{ Shoot height $(\mathrm{cm})$} \\
\hline A & $1.73 \pm 0.05$ & $2.36 \pm 0.05$ & $2.97 \pm 0.14$ & $2.35 \pm 0.08$ \\
\hline $\mathrm{B}$ & $1.93 \pm 0.03$ & $2.29 \pm 0.09$ & $3.53 \pm 0.23$ & $2.58 \pm 0.12$ \\
\hline $\mathrm{C}$ & - & - & - & - \\
\hline control & $2.18 \pm 0.06$ & $3.21 \pm 0.08$ & $4.65 \pm 0.25$ & $3.35 \pm 0.13$ \\
\hline Mean & $1.95 \pm 0.05$ & $2.62 \pm 0.08$ & $3.72 \pm 0.22$ & \multirow[b]{2}{*}{-} \\
\hline Least significant differences $(\mathrm{P}<0.05)$ & 0.16 & 0.23 & 0.64 & \\
\hline & \multicolumn{4}{|c|}{ Number of leaves } \\
\hline A & $5.40 \pm 0.40$ & $6.20 \pm 0.25$ & $6.40 \pm 0.37$ & $6.00 \pm 0.34$ \\
\hline B & $6.60 \pm 0.26$ & $5.80 \pm 0.35$ & $7.20 \pm 0.25$ & $6.53 \pm 0.28$ \\
\hline $\mathrm{C}$ & - & - & - & - \\
\hline control & $6.30 \pm 0.26$ & $6.0 \pm 0.26$ & $7.60 \pm 0.33$ & $6.63 \pm 0.28$ \\
\hline Mean & $6.10 \pm 0.32$ & $6.03 \pm 0.29$ & $7.07 \pm 0.32$ & \multirow[b]{2}{*}{-} \\
\hline Least significant differences $(\mathrm{P}<0.05)$ & 0.92 & 0.84 & 0.94 & \\
\hline & \multicolumn{4}{|c|}{ Number of shoots per explant } \\
\hline $\mathrm{A}$ & $1.0 \pm 0.25$ & $4.40 \pm 0.31$ & $2.80 \pm 0.29$ & $2.73 \pm 0.28$ \\
\hline $\mathrm{B}$ & $1.5 \pm 0.27$ & $3.10 \pm 0.41$ & $3.20 \pm 0.55$ & $2.6 \pm 0.41$ \\
\hline $\mathrm{C}$ & - & - & - & - \\
\hline control & $2.0 \pm 0.29$ & $5.20 \pm 0.42$ & $3.60 \pm 0.31$ & $3.6 \pm 0.34$ \\
\hline Mean & $1.53 \pm 0.28$ & $4.23 \pm 0.38$ & $3.20 \pm 0.40$ & \\
\hline Least significant differences $(\mathrm{P}<0.05)$ & 0.82 & 1.10 & 1.17 & - \\
\hline
\end{tabular}

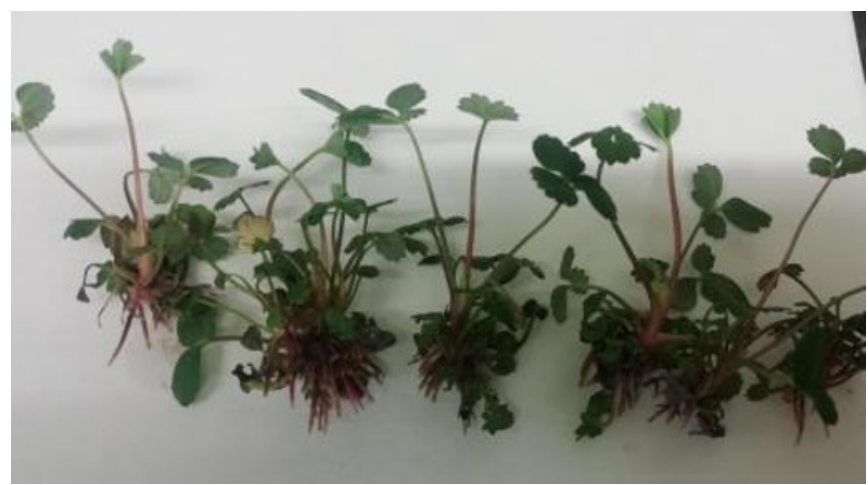

$\mathrm{a}(\mathrm{C})$

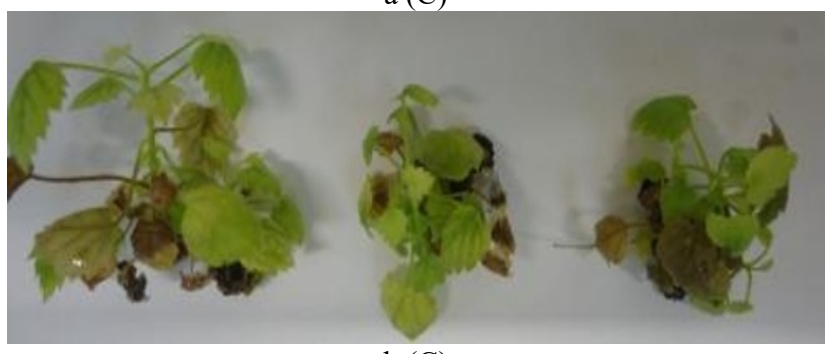

$\mathrm{b}(\mathrm{C})$

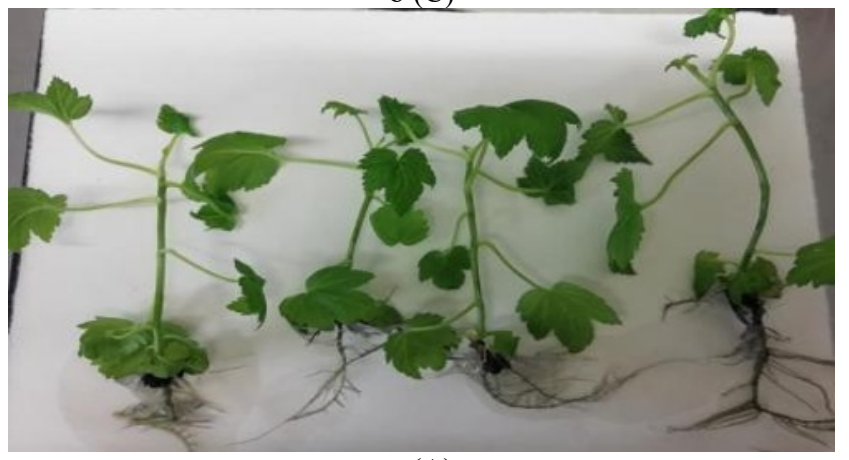

c (A)

Fig. 2. Regenerating plantlets of plum evaluated after the third subculture under standard medium, temperature, and light conditions after cold storage (bar $10.0 \mathrm{~mm}$ ). Genotypes: a strawberry variety 'Nashe Podmoskov'e', b raspberry cultivar 'Bryanskoe Divo', c black currant variety 'Bryanskiy Agat' examples were cold preserved in the Murashige-Skoog medium supplemented with (A) $0.45 \%$ of mannitol, $0,7 \mathrm{mg} \mathrm{L}^{-1} \mathrm{BAP}, 0,1 \mathrm{mg} \mathrm{L}^{-1}$ IBA and (C) $3 \%$ of sucrose $0,7 \mathrm{mg} \mathrm{L}^{-1} \mathrm{BAP}$ and $0,1 \mathrm{mg} \mathrm{L}^{-1}$ IBA. 


\section{Conclusion}

Morphometric indicators of the development of regenerated plants on a nutrient medium after the action of mannitol with different concentrations differed depending on the species and variety. It was established that in all studied berry crops, along with the growth of the main shoot, a new shoot formation was observed. The most active formation of adventitious shoots was noted in the raspberry variety 'Bryanskoe Divo', which formed an average of $5.20 \pm 0.42$ shoots per explant in the second subculture. At the same time, shoots with several nodes developed that could be cut for further propagation. When studying the effect of the reproduction cycle on the morphogenesis of meristemic cultures, it was found that the dynamics of changes in shoot length and number of leaves depended on the concentration of the active substance. So, for example, the shoot length at different concentrations of mannitol for black currant variety 'Bryanskiy Agat' by the second passage of development was $8.20 \pm 0.64 \mathrm{~cm}$ on nutrient medium $\mathrm{A}$ and $7.37 \pm 0.48 \mathrm{~cm}$ on medium $\mathrm{C}$, and the shoot length increases to $8.79 \pm 0.34$ and $9.10 \pm 0.40 \mathrm{~cm}$, respectively. In variant $\mathrm{C}$ of the experiment, the maximum number of leaves was also noted.

\section{References}

1. P. W. Jackson, K. Kennedy, Trends Plant Sci. 14, 578 (2009)
2. Gene bank standards for plant genetic resources for food and agriculture: Second edition, corrected and amended. (FAO, Rome, 2015).

3. N. I. Dzyubenko, Biopreserv. Biobanking, 16(5), 377 (2018)

4. F. Engelmannn, In Vitro Cell. Dev. Biol. Plant 47, $5(2011)$

5. M. Lambardi, C. Ruta, "Biotechnology for plant genetic resources conservation: an overview of in vitro-banking and cryobanking in the world", in the VIII International Scientitific and Practical Conference «Biotechnology as an Instrument for Plant Biodiversity Conservation (physiological, Biochemical, embryological, genetic and legal aspects)», p. 15, 2018

6. D. Shah, N. Sajjad, R. Ali, N. Nazir, S. Hassan and S. Shah, Plant Signaling Molecules, 257-268 (2019)

7. A. Lisek, T. Orlikowska, Acta Hortic., 560, 189 (2001)

8. A. Lisek, T. Orlikowska, Biotechnologia 3, 237 (2001)

9. A. Vinoth, R. Ravindhran, IJCOA 02, 268 (2013)

10. A. Lisek, T. Orlikowska, PCTOC 78, 167 (2004)

11. H. T. Gomes, P. M. C. Bartos, M. de A. Teixeira, R. F. Almeida, L. de L. Florencio, J. E. Scherwinski-Pereira, Pesq. agropec. bras., 52(12), 1286 (2017) 